\title{
AMENDMENTS
}

\section{Author Correction: Direct observation of coherent femtosecond solvent reorganization coupled to intramolecular electron transfer}

Elisa Biasin (D), Zachary W. Fox, Amity Andersen, Kathryn Ledbetter (D), Kasper S. Kjær, Roberto Alonso-Mori (D), Julia M. Carlstad (D), Matthieu Chollet, James D. Gaynor, James M. Glownia, Kiryong Hong (D), Thomas Kroll, Jae Hyuk Lee (D), Chelsea Liekhus-Schmaltz, Marco Reinhard (D), Dimosthenis Sokaras, Yu Zhang, Gilles Doumy (D), Anne Marie March, Stephen H. Southworth (D), Shaul Mukamel D, Kelly J. Gaffney (D), Robert W. Schoenlein (D), Niranjan Govind (D), Amy A. Cordones (D) and Munira Khalil (D)

Correction to: Nature Chemistry https://doi.org/10.1038/s41557-020-00629-3, published online 15 February 2021.

In the version of this Article originally published, in Fig. 4 the $x$-axis label was incorrect as 'Time (ps)'; it should have been ' $Q\left(\AA^{-1}\right)$ '. In addition, in the Fig. 4 key the labels for the green circle and red cross were mistakenly swapped; they should have been 'Solute-solvent dielectric' and 'Solute-solvent mechanical', respectively. These errors have now been corrected.

Published online: 24 February 2021

https://doi.org/10.1038/s41557-021-00663-9

This is a U.S. government work and not under copyright protection in the U.S.; foreign copyright protection may apply 2021

\section{Publisher Correction: Stereodefined alkenes with a fluoro-chloro terminus as a uniquely enabling compound class}

Qinghe Liu(D), Yucheng Mu(D), Tobias Koengeter (D), Richard R. Schrock and Amir H. Hoveyda (D)

Correction to: Nature Chemistry https://doi.org/10.1038/s41557-022-00893-5, published online 17 February 2022.

In the version of this article initially published, a conversion process led to label alignment errors in Figs. 1a, 2b, 3d, 5b-d and 6b,c and in Tables 1 and 2. There were also errors in functional groups in the two structures of the difluoro analogues of rumenic ester in the top right of Fig. 2b; in the top structure, " $\mathrm{MeO}_{2} \mathrm{C}$ " first appeared as " $\mathrm{H}_{2} \mathrm{CO}_{2} \mathrm{Me}$ ", and in the bottom structure, " $\mathrm{CO}_{2} \mathrm{Me}^{\text {" initially appeared as }}$ " $\mathrm{MeO}_{2} \mathrm{CH}_{2}$ ". The errors have been corrected in the HTML and PDF versions of the article.

Published online: 24 March 2022

https://doi.org/10.1038/s41557-022-00930-3

๑ The Author(s), under exclusive licence to Springer Nature Limited 2022 